\title{
Participation of Shepherd Families in Migratory Deccani Sheep Rearing
}

\author{
Geeta Gadekar* and Annapurna Kalal \\ Department of Extension and Communication Management, College of Community Science, \\ University of Agricultural Sciences, Dharwad, India \\ *Corresponding author
}

\section{A B S T R A C T}

Keyw or d s
Gender wise
participation,
Migratory Deccani
sheep rearing
families

Traditionally sheep rearing system has either been stationary or migratory. Migratory sheep rearing is quite common among the economically weaker sections of the society, which continues to be an important source of income and employment. The study on migratory Deccani sheep rearing families in Belagavi district was undertaken during 2018. A total of 180 respondents (90 families) were selected by purposive snow ball sampling method. The primary data was collected with the help of self-structured pre -tested interview schedule. The data was analyzed using suitable statistical tests such as, frequency, percentages, z-test and correlation. The results revealed that men were prominent in the most of the outdoor activities and the women contributed in indoor sheep rearing activities. In all activities of sheep rearing, significant difference was seen in participation of men and women. Majority of men $(83.33 \%)$ were belonged to high category of participation and most $(90.00 \%)$ of the women had medium participation. Hence, the study suggests to plan various training programmes to educate the migrating shepherds for their better participation in sheep rearing activities to make it more profitable.

\section{Introduction}

Traditionally sheep rearing system has either been stationary or migratory. Migratory sheep rearing is quite common among the economically weaker sections of the society, which continues to be an important source of income and employment (Kumar et al., 2015).

The migratory system of sheep rearing takes two forms i.e., temporary and permanent migration. In temporary migration, due to lack of fodder and grazing lands in their natives shepherds migrate with their flock during the rabi season and return to their natives along with their flock during the onset of monsoon. During this period shepherds move from one place to another for 6-7 months relying on the crop residues of cultivated lands for feeding their sheep. In this type of migration the men may or may not be accompanied by their families. Other families may stay in their native place being engaged in agricultural work or agricultural wage earners. 
In permanent migration, shepherds migrate over long distances throughout the year in search of fodder and water resources. The flocks never go back to their native, but the shepherds may go back to his natives for short periods during which they ask siblings or close relatives to take care of the flock in their absence. Along the way the shepherds pen their sheep on agricultural farms where the harvesting has been completed. The stubble form the food for the sheep. It is a win-win situation for the shepherd and the farm owners. The animal droppings increase the soil fertility and the shepherds in addition to grazing their flock also receive cash/kind from the farmers.

The studies have shown that men \& women play specific role in sheep rearing. Men are more involved in grazing, health care, decision making and market related activities, whereas, women participate in colostrum feeding, grazing of animals, collection and disposal of droppings, feeding, watering, care of pregnant animals, care at lambing time, providing special feed to lambs and cleaning of pens. Thus, men and women are actively involved in sheep rearing.

Migratory sheep rearing is traditional occupation which has been carried over from generation to generation. Since migration is a unique condition, the roles and responsibilities of men and women may vary. Keeping this point in mind, the present study was conducted to know the participation of men and women in sheep rearing activities.

\section{Materials and Methods}

The present study was conducted in northern Karnataka by selecting migratory Deccani sheep rearing families belonging to Belagavi district. The samples for the study was selected by purposive snowball sampling method as the respondents were continuously on the move and were not available at any fixed place to interview.

Deccani sheep is one of the important breed being reared by a majority of the migrating shepherds of Belagavi district. A total of 180 respondents (90 families, consists of 90 men and 90 women) were selected. The data was analyzed using suitable statistical tests such as, frequency, percentages, z-test and correlation.

\section{Results and Discussion}

The participation of both men and women of Deccani sheep rearing families was collected and are presented in Table 1. The activities performed by men and women were studied with respect to management of nutrition, health, breeding, housing, marketing and general management.

\section{Feed and nutrition}

The results revealed that cent per cent men were involved in storage and packing of fodder during migration, watering of animals, colostrum feeding, feeding of lambs and grazing of sheep. Women involvement in these activities was about 97.00 per cent. Both men $(85.60 \%)$ and women $(90.00 \%)$ are not involved in purchase of fodder. Preparation of special feeds/concentrates was done by 87.80 per cent of men and 90.00 per cent of women. Silage preparation was not done by either men or women as they were migrating.

As in traditional male dominated societies, men are involved in outdoor activities such as farming, livestock, services etc., Migration is the activity where women alone cannot participate and the activities are divided among themselves. However, women are also involved in watering, colostrums feeding, feeding lambs and packing fodder during migration to feed young sheep. Women are 
involved in indoor activities such as cooking, domestic activities, feeding dogs, horses, caring of young sheep, packing materials in every migration.

\section{Health management}

A look at Table 1 indicates that health management was mainly performed by men. Cent per cent men are engaged in storage and packing of fodder during migration, watering of animals, colostrums feeding, feeding of lambs and grazing of sheep. Vaccination $(91.10 \%)$ and deworming of animals (97.80 $\%)$ were also performed by men. Special care to sick animal $(82.20 \%)$ was looked after by men. Cent per cent of both men and women did not maintain health card and were not involved in disinfection of shed. Women also perform health management activities such as care of newborn $(96.70 \%)$, identification of sick animals (96.70\%), lambing of animals $(75.00 \%)$ and providing medicines to sick animals $(67.80 \%)$.

This is because they cannot take the diseased animals to hospital and pharmacists. Women had knowledge about vaccination but her participation is less compared to men. Health records were not maintained by any shepherd families because of large flock size, illiteracy and they have never felt the need to maintain records.

\section{Breeding management}

An insight into Table 1 indicates that cent per cent of men participated in selection of ram for breeding, care of pregnant animal, care of young one and observation of pregnant sheep. Only 04.40 per cent of men were involved in castration. While, great majority of women (94.40\%) participated in care of pregnant sheep. Majority of women (74.40\%) involved in taking care of young ones and observation of pregnant sheep, nearly half of women
$(44.40 \%)$ participated in selection of ram for breeding.

Considerable percentages of women were also caring for pregnant sheep \& the young lambs. Traditionally the woman as nurturer of the family is also concerned with the care and feeding of the pregnant and young lambs.

\section{Housing management}

The housing management of sheep and arrangement for overnight stay during migration is a continuous activity as detailed in Table 1. Putting tent and pen is done by cent per cent of men. Women were also does the same activity $(86.70 \%)$. Collection and disposal of manure and cleaning of sheep shed/pen is done by cent per cent of men and 97.80 per cent of women. Disinfection of shed/pen is not done by both men and women. Only 17.80 per cent of men and 12.20 per cent of women were involved in construction separate pen for pregnant sheep. Most of shepherd families do not construct separate pen for pregnant sheep and diseased sheep. The reason is that construction of separate pen needs more time and labour. It also is not economical because of continuous migration.

\section{Marketing management}

All men respondents are involved in selection of sheep for sale and purchase. Only 11.10 per cent of women are involved in both of these activities. Getting credit and input is done by 62.20 per cent of men and only 02.20 per cent of women. Men were dominant in marketing activities. Traditionally, women are not involved in sale of farm produce, livestock etc., The social and prevailing gender roles do not allow women to do marketing. Therefore, in the present study the involvement of men in marketing activities is observed more. 


\section{General management}

Table 1 revealed that cent per cent of men were involved in packing of materials during migration and shearing of wool. Majority of men $(96.70 \%)$ participated in hoof trimming. Nearly one fifth of the men $(18.90 \%)$ were participated in dehorning. Ear tagging was not practiced among migratory sheep rearing. Only 03.30 per cent of men not participated in hoof trimming. In case of women, 74.40 per cent participated in package of materials during migration. Women did not involve in dehorning, hoof trimming and shearing.

It is women who prepare the horses for migration. They make them comfortable for the children to sit on the horse back. All the tent material and cooking utensils are also packed by women. Ear tagging was not done by these migratory sheep rearing families, because ear tagging of sheep is costly (for one sheep 150 rupees) and they have not felt the need for it.

Table.1 Participation in sheep rearing activities by respondents $n=90$

\begin{tabular}{|c|c|c|c|c|c|c|c|c|c|}
\hline \multirow{3}{*}{$\begin{array}{c}\text { Sl. } \\
\text { No. }\end{array}$} & \multirow[t]{3}{*}{ Activities } & \multicolumn{4}{|c|}{$\operatorname{Men}\left(\mathbf{n}_{1}=90\right)$} & \multicolumn{4}{|c|}{ Women $\left(n_{2}=90\right)$} \\
\hline & & \multicolumn{2}{|c|}{ Yes } & \multicolumn{2}{|c|}{ No } & \multicolumn{2}{|c|}{ Yes } & \multicolumn{2}{|c|}{ No } \\
\hline & & $\mathbf{f}$ & $\%$ & $\mathbf{f}$ & $\%$ & $\mathbf{f}$ & $\%$ & f & $\%$ \\
\hline 1 & \multicolumn{9}{|l|}{ Nutrition management } \\
\hline 1 & $\begin{array}{l}\text { Storage and packing of fodder } \\
\text { during migration }\end{array}$ & 90 & 100.00 & - & - & 87 & 96.70 & 03 & 03.30 \\
\hline 2 & Chaffing of fodder & 90 & 100.00 & - & - & 87 & 96.70 & 03 & 03.30 \\
\hline 3 & Purchase of fodder & 13 & 14.40 & 77 & 85.60 & 09 & 10.00 & 81 & 90.00 \\
\hline 4 & Preparation of special feeds & 11 & 12.20 & 79 & 87.80 & 09 & 10.00 & 81 & 90.00 \\
\hline 5 & $\begin{array}{l}\text { Purchase of special feeds/ } \\
\text { concentrates }\end{array}$ & 10 & 11.10 & 80 & 88.90 & 02 & 02.20 & 88 & 97.80 \\
\hline 6 & Watering of animals & 90 & 100.00 & - & - & 87 & 96.70 & 03 & 03.30 \\
\hline 7 & Colostrums feeding & 90 & 100.00 & - & - & 88 & 97.80 & 02 & 02.20 \\
\hline 8 & Feeding of lambs & 90 & 100.00 & - & - & 88 & 97.80 & 02 & 02.20 \\
\hline 9 & Preparation of silage & - & - & 90 & 100.00 & - & - & 90 & 100.00 \\
\hline \multirow[t]{2}{*}{10} & Grazing of sheep & 90 & 100.00 & - & - & 59 & 65.60 & 31 & 34.40 \\
\hline & Index of nutrition management & \multicolumn{4}{|c|}{60.88} & \multicolumn{4}{|c|}{50.88} \\
\hline 2 & \multicolumn{9}{|l|}{ Health management } \\
\hline 1 & Lambing of animals & 90 & 100.00 & - & - & 68 & 75.60 & 22 & 24.40 \\
\hline 2 & Removal of umbilical cord & 90 & 100.00 & - & - & - & - & 90 & 100.00 \\
\hline 3 & Care of newborn & 90 & 100.00 & - & - & 87 & 96.70 & 03 & 03.30 \\
\hline 4 & Care of lambed sheep & 90 & 100.00 & - & - & 67 & 74.40 & 23 & 25.60 \\
\hline 5 & Vaccination & 82 & 91.10 & 08 & 08.90 & 16 & 17.80 & 74 & 82.20 \\
\hline 6 & Deworming of animals & 88 & 97.80 & 02 & 02.20 & 16 & 17.80 & 74 & 82.20 \\
\hline 7 & Identification of sick animals & 90 & 100.00 & - & - & 87 & 96.70 & 03 & 03.30 \\
\hline 8 & Providing medicine to sick animals & 90 & 100.00 & - & - & 61 & 67.80 & 29 & 32.20 \\
\hline 9 & Maintaining health card & - & - & 90 & 100.00 & - & - & 90 & 100.00 \\
\hline 10 & $\begin{array}{l}\text { Special care/ nutrition for sick } \\
\text { animals }\end{array}$ & 74 & 82.20 & 16 & 17.80 & 63 & 70 & 27 & 30.00 \\
\hline \multicolumn{2}{|r|}{ Index of health management } & \multicolumn{4}{|c|}{87.22} & \multicolumn{4}{|c|}{57.55} \\
\hline
\end{tabular}




\begin{tabular}{|c|c|c|c|c|c|c|c|c|c|}
\hline \multirow{3}{*}{$\begin{array}{l}\text { Sl. } \\
\text { No. }\end{array}$} & \multirow[t]{3}{*}{ Activities } & \multicolumn{4}{|c|}{$\operatorname{Men}\left(n_{1}=90\right)$} & \multicolumn{4}{|c|}{ Women $\left(n_{2}=90\right)$} \\
\hline & & \multicolumn{2}{|c|}{ Yes } & \multicolumn{2}{|c|}{ No } & \multicolumn{2}{|c|}{ Yes } & \multicolumn{2}{|c|}{ No } \\
\hline & & $\mathbf{f}$ & $\%$ & f & $\%$ & f & $\%$ & $\mathbf{F}$ & $\%$ \\
\hline 3 & \multicolumn{9}{|l|}{ Breeding management } \\
\hline 1 & Selection of ram for breeding & 90 & 100.00 & - & - & 40 & 44.40 & 50 & 55.60 \\
\hline 2 & Care of pregnant animal & 90 & 100.00 & - & - & 85 & 94.40 & 05 & 05.60 \\
\hline 3 & Care of young one & 90 & 100.00 & - & - & 67 & 74.40 & 23 & 25.60 \\
\hline 4 & Observation of pregnant sheep & 90 & 100.00 & - & - & 67 & 74.40 & 23 & 25.60 \\
\hline 5 & Castration & 04 & 04.40 & 86 & 95.60 & - & - & 90 & 100.00 \\
\hline \multicolumn{2}{|c|}{ Index of breeding management } & \multicolumn{4}{|c|}{80.22} & \multicolumn{4}{|c|}{61.55} \\
\hline 4 & \multicolumn{9}{|l|}{ Housing management } \\
\hline 1 & Construction of tent/ pen & 90 & 100.00 & - & - & 78 & 86.70 & 12 & 13.30 \\
\hline 2 & Cleaning of shed/pen & 88 & 97.80 & 02 & 02.20 & 67 & 74.40 & 23 & 25.60 \\
\hline 3 & Disinfection of shed/ pen & - & - & 90 & 100.00 & - & - & 90 & 100.00 \\
\hline 4 & $\begin{array}{l}\text { Collection and disposal of } \\
\text { manure }\end{array}$ & 90 & 100.00 & - & - & 80 & 88.90 & 10 & 11.10 \\
\hline 5 & Separate pen for pregnant sheep & 16 & 17.80 & 74 & 82.20 & 11 & 12.20 & 79 & 87.80 \\
\hline \multicolumn{2}{|c|}{ Index of housing management } & \multicolumn{4}{|c|}{63.33} & \multicolumn{4}{|c|}{55.55} \\
\hline 5 & \multicolumn{9}{|l|}{ Marketing } \\
\hline 1 & Selection animal for sale & 90 & 100.00 & - & - & 10 & 11.10 & 80 & 88.90 \\
\hline 2 & $\begin{array}{l}\text { Selection of animal for } \\
\text { purchase }\end{array}$ & 90 & 100.00 & - & - & 10 & 11.10 & 80 & 88.90 \\
\hline 3 & Getting credit and input & 56 & 62.20 & 34 & 37.80 & 02 & 02.20 & 88 & 97.80 \\
\hline 4 & $\begin{array}{l}\text { Grading of wool \& sorting of } \\
\text { wool }\end{array}$ & - & - & 90 & 100.00 & - & - & 90 & 100.00 \\
\hline 5 & Maintaining of accounts & 49 & 54.40 & 41 & 45.60 & - & - & 90 & 100.00 \\
\hline 6 & Record keeping & - & - & 90 & 100.00 & - & - & 90 & 100.00 \\
\hline 7 & Milk & - & - & 90 & 100.00 & - & - & 90 & 100.00 \\
\hline \multicolumn{2}{|c|}{ Index of marketing management } & \multicolumn{4}{|c|}{45.39} & \multicolumn{4}{|c|}{03.69} \\
\hline 6 & General management & & & & & & & & \\
\hline $\mathbf{1}$ & Dehorning & 17 & 18.90 & 73 & 81.10 & - & - & 90 & 100.00 \\
\hline 2 & Hoof trimming & 87 & 96.70 & 03 & 03.30 & - & - & 90 & 100.00 \\
\hline 3 & Shearing & 90 & 100.00 & - & - & - & - & 90 & 100.00 \\
\hline 4 & Ear tagging & - & - & 90 & 100.00 & - & - & 90 & 100.00 \\
\hline 5 & $\begin{array}{l}\text { Package of materials during } \\
\text { migration }\end{array}$ & 90 & 100.00 & - & - & 67 & 74.40 & 23 & 25.60 \\
\hline \multicolumn{2}{|r|}{ Index of general management } & \multicolumn{4}{|c|}{62.66} & \multicolumn{4}{|c|}{14.66} \\
\hline & Over all participation & \multicolumn{4}{|c|}{68.06} & \multicolumn{4}{|c|}{43.70} \\
\hline
\end{tabular}


Table.2 Difference in participation of men and women in migratory

Deccani sheep rearing $n=180$

\begin{tabular}{|c|c|c|c|c|}
\hline \multirow[t]{2}{*}{$\begin{array}{l}\text { Sl. } \\
\text { No. }\end{array}$} & \multirow[t]{2}{*}{ Dimensions of knowledge } & $\operatorname{Men}\left(n_{1}=90\right)$ & $\begin{array}{c}\text { Women }\left(\mathbf{n}_{2}=\right. \\
90)\end{array}$ & \multirow[t]{2}{*}{ z- value } \\
\hline & & Mean (SD) & Mean (SD) & \\
\hline 1 & $\begin{array}{l}\text { Feed and } \\
\text { management }\end{array}$ & $06.38(00.61)$ & $05.89(01.04)$ & $03.83 * *$ \\
\hline 2 & Health management & $08.72(00.47)$ & $05.76(00.54)$ & $17.40 * *$ \\
\hline 3 & Breeding management & $04.01(00.18)$ & $03.08(01.04)$ & $08.37 * *$ \\
\hline 4 & Housing management & $03.17(00.37)$ & $02.78(01.02)$ & $03.38 * *$ \\
\hline 5 & Marketing management & $03.18(00.64)$ & $00.28(00.75)$ & $27.79 * *$ \\
\hline 6 & General management & $05.10(00.70)$ & $01.14(01.18)$ & $27.21 * *$ \\
\hline
\end{tabular}

Figures in parenthesis indicate percentage

**Significant at 0.01 level, $* * *$ Significant at 0.000 level

Table.3 Categorization of the respondents based on their participation in sheep rearing activities $n=180$

\begin{tabular}{|c|l|c|c|c|c|}
\hline Sl. & \multicolumn{1}{|c|}{ Categories } & \multicolumn{2}{c|}{ Men $\left(\mathbf{n}_{\mathbf{1}}=\mathbf{9 0}\right)$} & \multicolumn{2}{c|}{ Women $\left(\mathbf{n}_{\mathbf{2}}=\mathbf{9 0}\right)$} \\
\cline { 3 - 6 } No. & & $\mathbf{f}$ & $\mathbf{\%}$ & $\mathbf{f}$ & $\mathbf{\%}$ \\
\hline $\mathbf{1}$ & Low (Up to 14) & - & - & 08 & 08.89 \\
\hline $\mathbf{2}$ & Medium (15-28) & 15 & 16.67 & 81 & 90.00 \\
\hline $\mathbf{3}$ & High (29-43) & 75 & 83.33 & 01 & 01.11 \\
\hline
\end{tabular}

Table.4 Relationship between the independent variables with participation of men and women in migratory sheep rearing activities $n=180$

\begin{tabular}{|c|l|c|c|}
\hline Sl. & \multirow{2}{*}{ Independent variables } & \multicolumn{2}{|c|}{ 'r value' } \\
\cline { 3 - 4 } No. & & Men $\left(\mathbf{n}_{\mathbf{1}}=\mathbf{9 0}\right)$ & Women $\left(\mathbf{n}_{\mathbf{2}}=\mathbf{9 0}\right)$ \\
\hline $\mathbf{1}$ & Age & $-0.064 \mathrm{NS}$ & $0.039 \mathrm{NS}$ \\
\hline $\mathbf{2}$ & Education & $-0.179 \mathrm{NS}$ & $-0.001 \mathrm{NS}$ \\
\hline $\mathbf{3}$ & Size of the family & $-0.080 \mathrm{NS}$ & $0.263^{*}$ \\
\hline $\mathbf{4}$ & Land holdings & $0.354^{* *}$ & $0.085 \mathrm{NS}$ \\
\hline $\mathbf{5}$ & Annual income & $0.215^{*}$ & $-0.20^{*}$ \\
\hline $\mathbf{6}$ & Flock size & $0.026 \mathrm{NS}$ & $-0.215^{*}$ \\
\hline $\mathbf{7}$ & Urban contact & $-0.006 \mathrm{NS}$ & $-0.100 \mathrm{NS}$ \\
\hline $\mathbf{8}$ & Social participation & $-0.089 \mathrm{NS}$ & $-0.390^{* *}$ \\
\hline $\mathbf{9}$ & Information consultancy pattern & $0.867 * *$ & $0.375^{* *}$ \\
\hline $\mathbf{1 0}$ & Knowledge & & \\
\hline
\end{tabular}

*. Correlation is significant at the 0.05 level

**. Correlation is significant at the 0.01 level

NS-Non significant 
Differences in participation of men and women in migratory Deccani sheep rearing

It was evident from Table 2 that men and women differed significantly at 0.05 level on all dimensions i.e., feed \& nutrition, health, breeding, housing, marketing and general management. In all the activities of sheep rearing, significant difference was found in participation of men and women. Men's participation is more compared to women. Women in permanent migration are also performing all the domestic activities like cooking, feeding dogs, grazing horses, cleaning utensils, fetching drinking water, fuel wood and washing clothes etc, along with above mentioned sheep rearing activities. Women are involved in keeping horses ready for the next journey.

Annual income was significantly co-related with participation because as the income increases the flock size increases entailing more work and more participation. Thus both variables are positively related with participation.

Size of family and flock size are positively related to women's participation. As the family size increases women's participation in sheep rearing activities also increases. Large flock size also needs more participation of women. As annual family income increases women's participation decreases because they can hire labour for some of the activities.

Categorization of respondents based on their participation in sheep rearing activities

The data presented in Table 3 shows that majority of men $(83.33 \%)$ belonged to high participation category. While, 16.67 per cent had medium participation, none of them were in the low participation category. While, majority of the women $(90.00 \%)$ had medium participation, 08.89 per cent had low participation category and only 01.11 per cent belonged to high participation category. As in traditional male dominated societies, men are involved in outdoor activities such as farming, livestock, services etc. Women are involved in indoor activities such as cooking, domestic activities, feeding dogs, horses, caring of young sheep, packing materials in every migration (Table 4).

In conclusion it is clear from the above facts that men \& women play specific role in sheep rearing. Men are more involved in grazing, health care, decision making and market related activities, whereas, women participate in colostrum feeding, grazing of animals, collection and disposal of droppings, feeding, watering, care of pregnant animals, care at lambing time, providing special feed to lambs and cleaning of pens. Men play very prominent role in outdoor activities and women in indoor activities which needs more care and affection. Thus, men and women are actively involved in sheep rearing. As sheep rearing contribute to sustainable livelihood, there is need to provide trainings and enhance their educational level to make the sheep rearing as profitable enterprise.

\section{References}

Bhagyashri, Y., (2002). Participation on rural women in wool production. M. H. Sc Thesis, University of Agricultural Sciences, Dharwad, Karnataka (India).

Kumar, R., Singh, D. R., Kumar, S., Chahal, V. P., Chaudhary, K. and Shaloo, (2015). Migratory sheep production system and its impact on livelihood security of sheep households in Ajmer district of Rajasthan. Indian J. Animal Sci., 85: 522-524

Meena, M. L. and Dudi, A., (2015). Role performance in sheep farming activities in western rajasthan: a gender 
perspective. Journal of Krishi Vigyan, 3 (2): 89-92.

Mishra, A. K., Subramanyam, K. V., Vijay, S., Reddy, T. Y., Shivarudrappa, B. and Ramakrishna, Y. S., (2006). Improving the livelihood of landless and marginal farmers through sheep rearing in rainfed agro ecosystems of India. Livestock Research for Rural Development, 18 (5): 56-65.

Mohanasundarraj, G. B. and Tripathi, H., (2011) Role performance in goat farming activities in southern zone of India: a gender perspective. Indian Journal of Small Ruminants, 17 (1): 83 87.

Narmatha, N., Sakthivel, K. M., Uma, V., Jothilaksmi, M. and Anil, K., (2015). Gender analysis in participation and decision making pattern in small ruminants production system. Tamil Nadu Journal of Human Ecology, 49 (12): $149-152$.

Nukapur, B. Y., (2002). Participation of rural women in wool production. M. H. Sc. Thesis, University of Agricultural Sciences, Dharwad. Karnataka (India).

Paudel, L. N., Meulen, U. C., Dahal, H. and Gauly, M., (2009). Gender aspects in livestock farming: pertinent issues for sustainable livestock development in Nepal. Livestock Research for Rural Development, 21: 85-89.

Rajanna, N., Mahendar, M. and. Venkataramana, K., (2013). A study on migration pattern of sheep flocks in Telangana region of Andhra Pradesh. The Journal of Research, ANGRAU, 41 (1): $42-46$

\section{How to cite this article:}

Geeta Gadekar and Annapurna Kalal. 2021. Participation of Shepherd Families in Migratory Deccani Sheep Rearing. Int.J.Curr.Microbiol.App.Sci. 10(02): 2235-2242. doi: https://doi.org/10.20546/ijcmas.2021.1002.266 